\title{
CONDIÇÕES DE TRABALHO E SAÚDE NO CONTEXTO DA PREVIDÊNCIA SOCIAL EM SANTA CATARINA
}

\author{
WORKING CONDITIONS AND HEALTH IN THE CONTEXT OF \\ SOCIAL SECURITY IN SANTA CATARINA, BRAZIL \\ CONDICIONES DE TRABAJO Y SALUD EN EL CONTEXTO DEL \\ SEGURO SOCIAL EN SANTA CATARINA
}

\author{
Patrícia Martins Goulart ${ }^{1}$ \\ Francisco Antonio de Castro Lacaz ${ }^{2}$ \\ Edvânia Ângela de Souza Lourenço ${ }^{3}$
}

Resumo Objetivou-se, nesta pesquisa quanti e qualitativa, conhecer e analisar as condições de trabalho de servidores públicos que atuam no Instituto Nacional de Seguro Social vinculados à Previdência Social do sul de Santa Catarina, com atenção às implicações em sua saúde. Tratou-se de estudo exploratório, realizado de 2013 a 2017. Dele participaram 165 trabalhadores vinculados a 11 agências do Instituto Nacional de Seguro Social daquela região, que responderam a questionário com escalas sobre condições de trabalho e bem-estar, associadas a perguntas abertas. Em um segundo momento, adotou-se a técnica de narrativas, com a finalidade de complementar as informações. Os resultados das escalas de condições de trabalho (0-10) obtiveram média de 6,65 (DP $=1,39)$, enquanto no que se refere ao bem-estar (0-7) a média foi de $4,99(\mathrm{DP}=1,13)$. Observaram-se dilemas éticos decorrentes da qualidade do trabalho, na medida em que se prioriza o alcance de metas quantitativas, devido à penetração da lógica privada na gestão do trabalho no espaço público. Concluiu-se que as condições de trabalho e bem-estar trazem repercussões negativas para a saúde dos trabalhadores.

Palavras-chave gestão; trabalho; saúde; previdência social; trabalhadores.
Abstract The aim of this qualitative and quantitative research was to get to know and analyze the working conditions of the public servants who work at the National Institute of Social Security (from the Portuguese Instituto Nacional de Seguro Social) and have ties with the Social Security System in the south of the state of Santa Catarina, Brazil, focusing on the implications to their health. This exploratory research was performed between 2013 and 2017. The sample was composed of 165 workers from 11 agencies of the National Institute of Social Security in that region, who filled out a questionnaire with scales to rate working conditions and well-being in association with open questions. In a second moment, we adopted the narrative technique with the goal of complementing the data. The mean result of the working conditions scale (0-10) was 6.65 ( $\mathrm{SD}=1.39$ ); as for the well-being, the mean result of the scale (0-7) was 4.99 ( $\mathrm{SD}=1.13)$. We observed ethical dilemmas deriving from the quality of the work, with the prioritization of the fulfillment of quantitative goals due to the introduction of the logic of the private sector within the management of the work in the public sphere. We concluded that the working conditions and well-being have negative repercussions on the health of the workers.

Keywords management; work; health; social security; workers.

(cc) BY Este é um artigo publicado em acesso aberto sob uma licença Creative Commons. 


\section{Introdução}

Até a Constituição Federal de 1988, os mecanismos de proteção à saúde dos trabalhadores limitavam-se à medicina do trabalho e saúde ocupacional, cuja base conceitual busca a manutenção da força de trabalho por meio de ações de assistência sob responsabilidade das empresas e fiscalização a cargo do Ministério do Trabalho (Lacaz, 2007). A saúde do trabalhador surge como campo de práticas e saberes entre as décadas de 1970 e 1980 como uma nova abordagem, expressando a luta dos trabalhadores por maior representação política e por direitos básicos. Trata-se de um conceito que brota da saúde coletiva, o qual compreende o trabalhador como um sujeito multideterminado e também como um ator social, incorporando ainda o papel do trabalho na determinação do processo saúde/doença. Tal abordagem se atém à dimensão humana do trabalho e à proteção de agravos à saúde dos trabalhadores, tais como mal-estares, incômodos, desgastes, além dos acidentes e doenças (Lacaz, 2007).

Para os servidores públicos, não havia regulação nem instrumentos específicos de proteção à sua saúde. As medidas restringiam-se a licenças médicas e aposentadorias por invalidez (Martins et al. 2017). Um avanço ocorreu em 1993, com a criação do Grupo Executivo Interministerial em Saúde do Trabalhador (Geisat), cujo objetivo foi construir uma proposta para normalizar, regular e monitorar as relações de trabalho e saúde dos trabalhadores, incluindo os servidores públicos. Pressionados pelos movimentos sociais e influenciado por esse debate, o Ministério do Planejamento, Orçamento e Gestão (MPOG), com a participação de instituições públicas federais, representantes de sindicatos e gestores, fez uma tentativa de estruturar e regulamentar um sistema de proteção social para os servidores públicos, por meio do Sistema de Saúde Ocupacional do Servidor Público (Sisosp) (Martins, et al., 2017). Os debates com o foco no campo da saúde do trabalhador levaram à substituição do Sisosp pelo Subsistema Integrado de Atenção à Saúde do Trabalhador (SIASS) (Brasil, 2009). Tal subsistema pressupõe o protagonismo dos trabalhadores no que se refere à saúde, com atenção ao planejamento e implementação das ações de transformação dos processos de trabalho.

Embora se reconheça o avanço dos debates com a criação do SIASS, ainda não se concretizaram ações concretas na melhora da saúde e qualidade de vida dos servidores federais da Previdência Social (PS), conforme dados referentes a Santa Catarina (Sindicato dos Trabalhadores em Saúde e Previdência do Serviço Público Federal no Estado de Santa Catarina, 2013).

A partir desta constatação, os responsáveis pelo Serviço de Qualidade de Vida e Trabalho (SQVT) de uma gerência executiva do Instituto Nacional do Seguro Social (INSS) de Santa Catarina solicitaram parceria com uma universidade da região, para estudar as condições de trabalho em sua área 
de abrangência. Após diversas reuniões e fóruns com membros da mencionada gerência e demais trabalhadores, construiu-se o desenho do estudo aqui apresentado, com o objetivo de conhecer e analisar as condições de trabalho e seus desdobramentos na saúde dos servidores do INSS daquele território.

Chamou-nos a atenção a ínfima produção teórica acerca do tema, que se contrapõe à relevância do INSS, autarquia federal, responsável pelo gerenciamento do Regime Geral da Previdência Social (RGPS) no país. Um levantamento bibliográfico (Christo e Borges, 2017) identificou três artigos, quatro dissertações e uma tese doutoral nesse âmbito, sendo que cinco dessas publicações abordam o trabalho do médico-perito, dois o trabalho do assistente social e um o trabalho do técnico do seguro social.

Aqui, é importante destacarmos dois acontecimentos que atravessaram esse percurso: a extinção do Ministério da Previdência Social em 2016 e a greve de grande porte, por melhores condições de trabalho, empreendida em 2015 pelos servidores do INSS, com expressivo protagonismo de Santa Catarina.

Na primeira etapa desta pesquisa (2013-2015), o INSS estava vinculado ao Ministério do Trabalho e Previdência Social (MTPS), tendo a incumbência de receber as contribuições para a manutenção do RGPS, além de ser responsável pelo pagamento de benefícios como aposentadorias, pensões, auxílios-doença, dentre outros previstos em lei. Todavia, o MTPS foi absorvido pelo Ministério da Fazenda em 2016, juntamente com a Empresa de Tecnologia e Informações da Previdência Social (Dataprev). Além disso, o INSS foi vinculado ao Ministério de Desenvolvimento Social e Agrário (Brasil, 2016c).

Tais alterações ocorreram em meio ao conturbado processo de impeachment da presidente Dilma Rousseff, sob alegação de crime de responsabilidade fiscal (Brasil, 2016a). Esta situação foi tratada por alguns autores como um golpe institucional, possibilitado pela aliança entre as elites econômicas, financeiras e os partidos de oposição (Braz, 2017; Fagnani, 2016). Assim, desde agosto de 2016 o país passou a ser governado pelo então vice-presidente, que assumiu compromisso com a alegada modernização das leis trabalhistas e reforma da PS, visando à geração de empregos e ao crescimento econômico (Brasil, 2016b).

Além dessas mudanças, foram anunciadas modificações nas regras para o acesso aos benefícios da Previdência Social, alterando consagrados direitos sociais, com o argumento do déficit da PS. Sobre esta questão, já em meados dos anos 2000, Gentil (2006) atestava contabilmente que, ao contrário do discurso oficial, o sistema da PS era superavitário. Fagnani (2016), dez anos mais tarde, corroboraria esta tese, dentre outros autores (Lourenço, Lacaz e Goulart, 2017), evidenciando que os argumentos relacionados ao déficit não se sustentam.

Frise-se que o discurso presidencial está sintonizado com os pressupostos da Nova Gestão Pública (NGP) (Bresser-Pereira, 1997; Araújo e Castro, 2011), que, de modo geral, apregoa a redução de gastos pelo 'enxugamento' 
do Estado e o foco em metas e resultados quanto ao seu papel (Lacaz, Goulart e Junqueira, 2017).

Esse novo perfil do papel do Estado produz reflexos na gestão do trabalho no setor público, trazendo sobrecarga de trabalho e redução de direitos trabalhistas, a exemplo da terceirização ilimitada, aprovada na Reforma Trabalhista (Brasil, 2017) - o que atua na corrosão do emprego estável e no aumento da instabilidade social, com nocivas consequências sobre a vida dos trabalhadores (Souza e Mendes, 2016; Lourenço, 2015, 2016; Antunes e Druck, 2015; Lacaz, Goulart e Junqueira, 2017).

Como já apontado, em 2015 foi deflagrada a mais extensa greve de trabalhadores do INSS em Santa Catarina, a qual perdurou por quase três meses. Eram reivindicadas melhorias nas condições de trabalho; incorporação das gratificações; jornada de trinta horas semanais; reparação das perdas salariais; melhorias do serviço público e paridade entre ativos e aposentados. Conforme o Sindicato dos Previdenciários de Santa Catarina (Sindprev-SC), a greve foi suspensa em 30 de setembro de 2015 mediante alguns acordos, tais como: incorporação das gratificações pela média dos últimos cinco anos e menores prazos para o pagamento de reajuste salarial (Sindicato dos Trabalhadores em Saúde e Previdência do Serviço Público Federal no Estado de Santa Catarina, 2015). Em 2016, o sindicato recorreu juridicamente pelo cumprimento do que foi acordado porque ainda não havia sido contemplado (Silva, 2017). Embora a greve e os fatos político-administrativos apontados não constituam escopo da investigação, sinalizam as condições de trabalho dos servidores do INSS.

Outrossim, o equilíbrio contábil da PS é central no que tange ao orçamento da União, sendo ela uma das primeiras instituições a adotar os princípios da racionalização do trabalho e otimização dos recursos, com o argumento de aperfeiçoar o acesso dos serviços aos contribuintes (Prado e Duarte, 2015).

Diante desse panorama, buscamos aportar evidências empíricas sobre consequências das condições de trabalho na saúde dos trabalhadores do INSS de Santa Catarina, com especial atenção na (res)significação do trabalho e na emergência de tensões e dilemas ético-profissionais, assim como nas repercussões psicossociais decorrentes de determinadas condições de trabalho, regidas pela ótica da NGP (Araújo e Castro, 2011).

\section{O pano de fundo da pesquisa}

A partir dos anos 1970, a crise do capital atingiu a organização do Estado, impondo-se o mesmo processo de reestruturação produtiva adotado para a retomada das taxas de acumulação em outros setores da economia (Lacaz, Goulart e Junqueira, 2017) - o que afetou profundamente o mundo do trabalho e as políticas sociais. A flexibilização dos processos e relações de tra- 
balho, mediante adoção de novas regras e condicionantes para produção e consumo, confrontou duas características estruturantes da vida em sociedade erguidas no pós-Segunda Guerra: o modo de organizar o trabalho e a produção até então, estruturados no modelo fordista-taylorista; e a relação do Estado com a sociedade, cuja referência no pós-Segunda Guerra é o Estado de Bem-Estar Social (Laval e Dardot, 2016; Navarro e Lourenço, 2017).

Sobre o primeiro aspecto, é preciso ressaltar que na 'solução' da crise do capital adota-se a acumulação flexível para imprimir nova fase de acumulação, o que significa a desconcentração empresarial e do trabalho, a introdução de novos métodos de organização e gestão do trabalho (e produção) na busca da 'qualidade total'. Nesse sentido, o toyotismo é o novo modo de organizar o trabalho, o qual está assentado em princípios e diretrizes que colocam a produção das mercadorias subordinada ao consumo individualizado e os trabalhadores ajustados às novas necessidades empresariais (Antunes e Druck, 2015).

A intensa apropriação dos avanços tecnológicos pelo capital acompanha as mudanças no mundo do trabalho. Assim, outras características importantes do toyotismo surgem em íntima associação com as inovações tecnológicas, tais como automação, robótica, microeletrônica e telemática, permitindo desenvolver atividades a quilômetros e quilômetros da matriz, bem como o controle da produção e do trabalho. Isso é possível, sobretudo, pelas tecnologias da informação e da comunicação, as quais contribuíram para assegurar o êxito do novo modo de organizar o trabalho e a produção (Alves, 2011; Lima, 2013).

O capital, diante das crises que lhe são próprias, cobra do Estado garantias para a retomada das taxas de acumulação; portanto, as mudanças no mundo do trabalho foram acompanhadas das mudanças do papel do Estado e da sua relação com a sociedade - e têm no neoliberalismo sua sustentação políticoideológica, com restrições para a legislação relativa aos direitos trabalhista e social (Anderson, 1995).

Assim, no Brasil, a partir de 1980, ocorreu um duplo movimento: se, por um lado, a luta da sociedade pelo fim da ditadura empresarial-militar e pelo Estado Democrático de Direito resultou em direitos civis, políticos, sociais e trabalhistas constitucionalmente garantidos, por outro o Estado, atendendo ao mercado, impôs, a partir de 1990, duras restrições ao acesso às políticas sociais, afastando o cariz universal para efetivá-las de forma parcial, fragmentada e cada vez mais focalizada (Lourenço, 2016).

O avanço do ideário neoliberal, apoiado pelos organismos internacionais como Banco Mundial e Fundo Monetário Internacional (FMI), expresso no Consenso de Washington, defende que se o Estado gasta menos na área social e privatiza os respectivos serviços cria maior competitividade e mais eficiência, contribuindo para o crescimento e o retorno do emprego, embora estudos evidenciem que o neoliberalismo fracassou nesta empreitada (Bandeira, 2002; Gonçalves, 2012). 
A NGP, originada sob preceitos neoliberais, com a justificativa de combater a ineficiência dos serviços públicos, encobre processos de trabalho mecanizados e desprovidos do espírito ético-político pertinente aos serviços humanos, com desdobramentos sobre a saúde dos sujeitos envolvidos (Lacaz, Goulart e Junqueira, 2017).

A PS incorpora esses processos de gestão do trabalho centrados em metas e resultados, num projeto de modernização que prevê mudanças na gestão de pessoas e melhoria das tecnologias de informação (Dataprev, 2013).

Constatou-se que a lógica centrada no mínimo de investimentos com máximo de rendimentos, apoiada pelos pressupostos da NGP, tem sido transposta para instituições públicas, com repercussões sobre a saúde dos trabalhadores (Sennett, 2006; Blanch e Stecher, 2010; Traesel e Merlo, 2014; Christo e Borges, 2017) que precisam ser mais exploradas.

Para além da ausência de doenças, a concepção de saúde aqui adotada vincula-se à de bem-estar, o qual pode ser compreendido como um conjunto de juízos valorativos e de reações emocionais concernentes ao grau de satisfação, prazer e felicidade com a própria vida (Diener, Tay e Oishi, 2013). E condições de trabalho, categoria-chave neste estudo, são definidas como um conjunto de circunstâncias e características ecológicas, materiais, técnicas, econômicas, sociais, políticas, jurídicas e organizacionais no marco das quais se desenvolvem as atividades e as relações laborais (Blanch, Sahagún e Cervantes, 2010).

\section{Delineamento metodológico}

Objetivamos conhecer e analisar as condições de trabalho dos trabalhadores do INSS no sul catarinense e especificamente responder a perguntas relacionadas às circunstâncias e características materiais, técnicas, econômicas, sociais, jurídicas e organizacionais dentro das quais se desenvolvem as atividades e relações de trabalho, como também investigar a percepção acerca da saúde e do bem-estar no trabalho. Tratou-se de investigação de caráter descritivo, com abordagem qualiquantitativa.

O levantamento de dados desenvolveu-se em duas etapas, ambas com suporte institucional. Na primeira, de cunho qualiquantitativo, ocorrida entre 2013 e 2015, em que foi aplicado um questionário misto (Blanch et al., 2010), houve apoio de editais internos de uma universidade catarinense. Na segunda etapa, de 2016 a 2017, foram colhidas narrativas que versavam sobre trajetórias de trabalho, visando ao aprofundamento dos dados obtidos na primeira etapa. Esta segunda etapa ocorreu no estágio de pós-doutorado em uma universidade federal, com apoio parcial na forma da bolsa da Coordenação de Aperfeiçoamento de Pessoal de Nível Superior (Capes). 
O campo da investigação envolveu uma gerência executiva do INSS, que compreende 11 agências que atendem 42 municípios, com um total de 248 servidores.

A dimensão quantitativa do estudo utilizou amostra de conveniência, intencional e estratificada, segundo critérios de inclusão que consideraram a heterogeneidade no que se refere a sexo, idade, função e antiguidade na organização. Excluíram-se aqueles sujeitos que estavam em afastamento do trabalho. A amostra foi composta de 165 sujeitos. Os dados numéricos foram levantados mediante aplicação do questionário mencionado, o qual contém seis escalas específicas sobre condições de trabalho (Blanch, Sahagún e Cervantes, 2010) e duas escalas relativas a bem-estar laboral (Blanch et al., 2010). Estas escalas foram validadas num contexto ibero-americano e relacionam-se com um modelo teórico (Blanch, Sahagún e Cervantes, 2010) que configura uma tríplice relação entre organização, ambiente laboral e o trabalhador. Neste modelo (Figura 1), as condições de trabalho são avaliadas considerando-se a relação entre a organização e o método de trabalho; a organização e o ambiente de trabalho; e a organização e a pessoa que trabalha. Ao considerarem as circunstâncias de trabalho, os enunciados convidam: "Valore os seguintes aspectos em suas condições de trabalho". As escalas são do tipo Likert, abarcando um intervalo que se estende de ' 0 ' (valor 'péssimo') a '10' (valor 'ótimo'). As escalas que versam sobre o bem-estar laboral foram validadas no contexto brasileiro (Goulart et al., 2012) e configuram um modelo teórico (Figura 2) (Blanch et al., 2010) com duas dimensões principais: bem-estar psicossocial e efeitos colaterais. Para responder às perguntas que correspondem ao bem-estar psicossocial, o sujeito deve colocar-se na seguinte situação: "Atualmente, em meu trabalho, sinto..." E quanto aos efeitos colaterais: "Atualmente, por causa de meu trabalho, sinto..." Neste caso, as escalas Likert abarcam um intervalo que se estende de ' 0 ' (valor ‘mínimo') a ‘10' (valor ‘máximo'), e ‘0’ (valor 'mínimo') a ‘7' (valor ‘máximo'), como será detalhado na apresentação de resultados.

\section{Figura 1}

Modelo teórico - Condições de trabalho

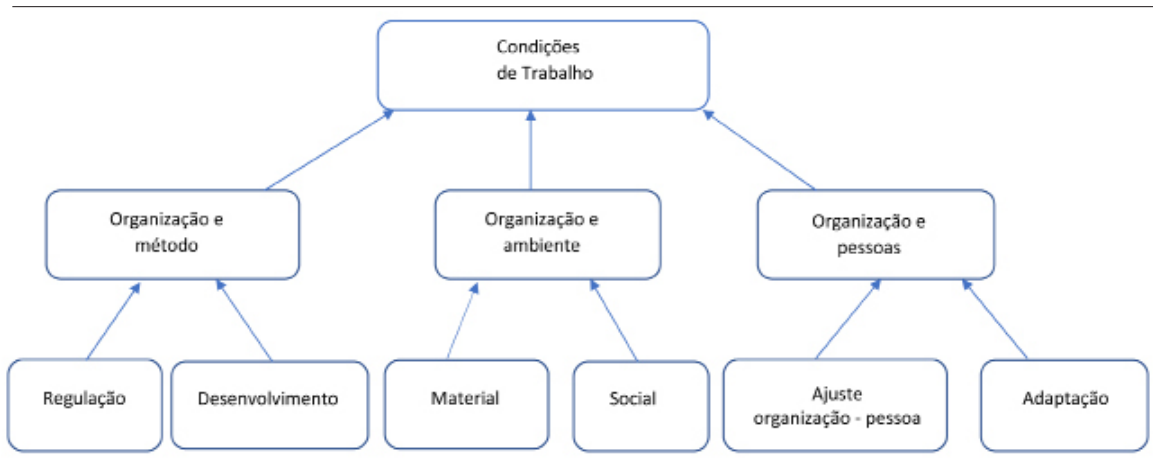

Fonte: Extraído de Blanch, Sahagún e Cervantes, 2010

Nota: O.P.: organização e pessoas. 
O questionário contém ainda três questões abertas que convidam o participante a comentar: 1. a) Quatro palavras-chave que definem a sua experiência de trabalho atual. 2. Das condições de trabalho (materiais, sociais, técnicas, financeiras, contratuais, temporais etc.): bl) O que está melhorando? b2) O que está piorando? 3. c) Para realizar o seu trabalho, o tempo é suficiente, sobra tempo ou falta? O questionário inclui uma ficha de instruções e dados demográficos.

Figura 2

Modelo teórico - saúde e bem-estar

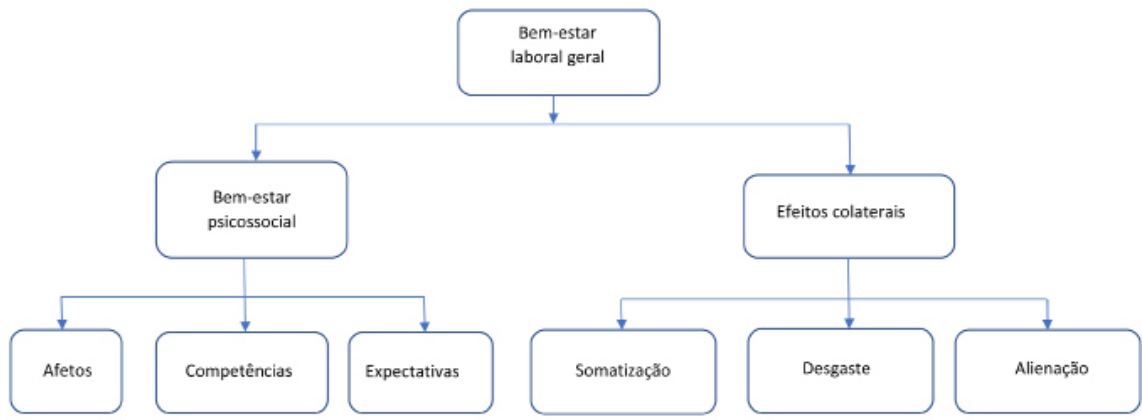

Fonte: Extraído de Blanch et al., 2010.

Os passos da investigação, em sua primeira etapa, incluindo divulgação, propósitos e convite para participação, foram publicados por meio de e-mail institucional encaminhado por gestora responsável pelo SQVT às mencionadas agências. $\mathrm{O}$ instrumento foi aplicado presencialmente em todas as agências do INSS de abrangência do estudo, mediante um cronograma prévio e com apoio de servidores contatados previamente, além de uma bolsista de iniciação científica. Após uma preleção sobre os propósitos da pesquisa, com espaço para dúvidas e comentários, os participantes foram convidados a preencher o instrumento em uma sala reservada para esse fim no próprio local de trabalho. O tempo médio de duração das aplicações foi de uma hora.

Na segunda etapa, os servidores foram convidados, por meio de e-mail institucional, a relatarem a sua trajetória de trabalho, como já dito, na forma de narrativas. As narrativas são ferramentas não estruturadas, que buscam aprofundar aspectos específicos de um objeto, com base nas quais emergem histórias de vida, tanto do entrevistado como as entrecruzadas no contexto situacional da pesquisa (Muylaert et al., 2014). 
Os participantes foram contatados por um dos pesquisadores a fim de agendar horário para relato da trajetória de trabalho na instituição, por meio de áudio e voz. Cuidamos de fazer contato em todas as agências visando obter maior contraste de informações, sem nos atermos a generalizações de conteúdos. Esta fase do estudo restringiu-se a nove narrativas, em parte porque houve uma desaceleração do processo de participação por conta dos mencionados acontecimentos político-administrativos e porque as informações mostraram-se suficientes. O levantamento de informações mediante narrativas não contou com um roteiro estruturado, sendo solicitado aos participantes que relatassem sua história de trabalho a partir do viés cronológico que lhes parecesse mais conveniente. Ocorreram duas reuniões a distância com os narradores, com duração média de uma hora, para esclarecimentos acerca da história de trabalho.

Para a organização e a análise dos dados quantitativos utilizou-se o pacote estatístico SPSS 19.0, enquanto as perguntas abertas foram analisadas com o apoio do programa Sphinx (Freitas e Moscarola, 2000).

$\mathrm{O}$ tratamento das informações relacionadas às narrativas foi inspirado no método de Meihy (2005), centrado na história oral, com interesse em que o narrador elucidasse algum evento específico ou opinasse sobre ele.

Os participantes assinaram Termo de Consentimento Livre e Esclarecido, e o projeto foi aprovado nas duas etapas: a primeira certificada pelo Comitê de Ética em Pesquisa (CEP) da Universidade do Extremo Sul Catarinense (Unesc), com o n. 20666813.8.0000.0119, em 08/08/2013; e a segunda pelo CEP da Universidade Federal de São Paulo (Unifesp), com o n. 37296614.6.0000.5505, em 26/02/2015.

\section{Resultados e análise}

Responderam ao questionário 165 servidores, o que representa $66,5 \%$ da população geral $(\mathrm{N}=265)$, com faixa etária média de 42,9 anos, sendo $62,6 \%$ mulheres e $37,4 \%$ homens. O tempo médio de serviço foi de 21 a 30 anos, dos quais $38,3 \%$ tinham familiaridade com cargos de gestão. A escolaridade predominante era universitária. A jornada de trabalho completa era exercida por $62,6 \%$ (oito horas diárias) dos servidores, enquanto $27,6 \%$ atuavam em jornada parcial (seis horas diárias).

Das narrativas, concederam informações nove servidores, sendo seis do sexo feminino e três do masculino, de diferentes agências e funções, com tempo de serviço de oito a vinte anos, nível universitário e jornada de trabalho completa, representados por N1 (narrador 1) a N9 (narrador 9).

Os resultados que envolvem condições de trabalho - ou seja, a relação da organização $(\mathrm{O})$ com o método de trabalho $(\mathrm{M})$; da organização $(\mathrm{O})$ com o 
ambiente de trabalho (A); e da organização (O) com a pessoa (P) - são descritos a seguir.

De modo geral, o conjunto de escalas referentes às condições de trabalho (0-10) obteve média 6,65 DP=1,39.

Segue a análise dos aspectos mais relevantes.

\section{Jornada e ritmo de trabalho, remuneração e relação trabalho-vida privada}

A escala sobre o tempo de trabalho, retribuição econômica, conciliação do trabalho com a vida privada e familiar (0-10) obteve média de 6,66 (DP=1,71), enquanto a escala relativa à autonomia na tomada de decisões, justiça na contratação e apoio recebido dos gestores, 6,03 (DP=1,95).

Adotando as orientações de Blanch (2014) consideramos que a valoração mínima representa condições de trabalho aquém do esperado, e a valoração máxima, condições ideais para o desenvolvimento do trabalho. Assim, as médias aqui obtidas assemelham-se a um copo de água parcialmente cheio. Os relatos textuais oriundos das narrativas e perguntas abertas auxiliaram a identificar a parte vazia do copo, como procuramos descrever.

A baixa remuneração foi recorrente nas narrativas (N1, N5, N8), assim como o baixo número de trabalhadores em comparação com a demanda de trabalho. Soma-se a isso o adiamento da aposentadoria visando manter gratificações e assim evitar redução salarial, como segue:

Não sei se algum servidor relatou a questão do IMA [Índice Média de Acervo], um índice institucional de avaliação de desempenho. Então, a nossa remuneração é abaixo do mínimo, o resto é penduricalho. (...) Acho que é um modo de pressão (N9).

Segundo os relatos (N1, N8, N9), a gratificação é desproporcional às exigências decorrentes de metas, levando à sobrecarga, expressa em horas de trabalho e acúmulo de funções, como no caso dos gestores:

Atualmente, o gerente trabalha praticamente sozinho na gestão, as chefias de benefícios e supervisores operacionais deixaram de existir por conta da irrisória gratificação, em contrapartida com a carga horária de oito horas. O gerente acumula funções (N4).

Tal sobrecarga dificulta a separação trabalho e vida privada, gerando ansiedade e outras repercussões:

Aí tu já não sabe [sic] mais o que fazer com tanto processo acumulado e vem a chefia dizer que tem que abrir mais vagas de agendamento, pois o agendamento está 
caindo para mais de trinta dias e está impactando no índice ' $\mathrm{x}$ ' . (...) Sentia tontura, ansiedade. Precisei fazer terapia e com o tempo aprendi a separar as coisas (N8).

No que se refere ao ritmo de trabalho, cumpre citar os dados relacionados à pergunta aberta n. 3c: "Para realizar o seu trabalho, o tempo é suficiente, sobra ou falta?"

A análise indicou que uma quantidade pequena dos participantes $(12 \%)$ refere que sobra tempo para o cumprimento das tarefas, enquanto a maioria alegou que falta tempo (56\%) ou é suficiente (26\%), sendo que $6 \%$ não responderam a esta pergunta.

As narrativas ilustraram a 'falta de tempo' com ênfase nas reações de impaciência e sofrimento que tal situação provoca, além de enfatizar o 'tempo corrido', que se contrapõe à qualidade do atendimento, trazendo dúvidas sobre sua continuidade, quando interrompido e retomado por outro colega.

(...) em grande parte dos casos, não consigo acompanhar o processo que iniciei até o final, uma vez que atendo muitos agendamentos, e em razão das metas outro colega acaba finalizando muitos processos. Uma preocupação era se o colega que desse continuidade ao caso seria cuidadoso seguindo tudo o que está escrito na instrução normativa e tudo o que eu já havia orientado o segurado no primeiro atendimento (N8).

Comecei a carreira no setor de atendimento, na época, orientação e informação, mas fiquei pouco tempo e fui para a perícia médica. O trabalho era fácil, mas meio corrido (N7).

A lógica e o ritmo, como se observou nas narrativas, levam à fragmentação do processo de trabalho, comprometendo o acompanhamento das diferentes etapas dos processos dos segurados. Além do mal-estar gerado, decorrente dessa fragmentação, há consequências imprevisíveis para os segurados, "pois o servidor não sabe como o colega agirá na continuidade do processo" (N8).

Cumpre destacar que o modelo de gestão adotado trouxe alguns benefícios em termos de agilidade, como redução de filas, uma vez que os agendamentos ocorrem por telefone e há maior transparência nos processos, por meio da ouvidoria pública. Para alguns servidores, como os médicos peritos, as alterações em curso trazem boas expectativas, o que não é visto da mesma forma por servidores de outras categorias, quando se referem às metas progressivas:

Desde meu ingresso no INSS, estou na atribuição de médico perito, tenho uma boa expectativa com tudo que vem ocorrendo de mudanças dentro da instituição (N2). 
Então, em 2008, começou um sistema de metas e gratificação por desempenho. Aquilo me pareceu uma coisa boa, pois eu tinha uma esperança de que o trabalho ficasse mais organizado. Por um lado ficou... O problema é que com o tempo as metas foram aumentando e chegaram a um patamar humanamente impossível de atingir... (N9).

Estudos apontam as frequentes situações de litígio entre os segurados e a autarquia previdenciária, mediadas pela atuação dos servidores diante dos conflitos. Destacam o despreparo dos servidores para atuarem na função pública, ao que se soma o desconhecimento da legislação previdenciária. Do ponto de vista da gestão, ressaltam a sobrecarga agora imposta pelo cumprimento de metas ou mesmo o descumprimento do princípio de observância da oficialidade, os quais implicam, muitas vezes, a restrição de acesso ao benefício a que o segurado teria direito (Triches, 2012).

Além disso, a escassez orçamentária e o déficit no quadro de servidores são considerados disparadores dos indeferimentos. Ribeiro e Mancebo (2013) acrescentam a inexistência de condições adequadas para o desenvolvimento do trabalho, os baixos salários e a impossibilidade de ascensão na carreira.

\section{A organização, o ambiente e o 'clima' de trabalho}

Os resultados numéricos acerca do 'ambiente material', ou seja, instalações, recursos materiais, prevenção de riscos no trabalho, serviços auxiliares, e do 'ambiente social' - companheirismo, respeito ao grupo de trabalho, reconhecimento do trabalho pelos colegas e por parte dos usuários (0-10) - tiveram o escore de 5,92 $(\mathrm{DP}=2,06)$ para o ambiente material e de 7,39 $(\mathrm{DP}=1,60)$ para o ambiente 'social'.

O item 'Reconhecimento do trabalho por parte dos colegas' $(8,86)$ obteve a maior frequência de respostas, seguido de 'Respeito no grupo de trabalho' e 'Reconhecimento do trabalho por parte dos usuários'. A parte vazia do corpo, ou o lado escuro do ambiente de trabalho, diz respeito à 'Prevenção de riscos no trabalho', o qual obteve a menor frequência de pontuação $(5,56)$, sugerindo descaso com medidas de proteção à saúde. Os aspectos referentes à 'Prevenção de riscos no trabalho' conectam-se às precárias condições do ambiente material, como relatado:

O espaço físico é inadequado... falta de impressoras, ou equipamentos que não funcionam. A estrutura é bem precária. Por exemplo, tem um equipamento que precisa ficar em lugar refrigerado (...) A gente chama a sala de geladeira (N9).

Ainda sobre as condições ambientais e relações de trabalho, os resultados textuais da pergunta aberta n. 3. c) indicaram que o companheirismo, a esta- 
bilidade e o horário configuram 'o melhor do trabalho', enquanto as metas, o salário e a falta de estrutura física são o que existe de 'pior no trabalho'.

O 'Respeito no grupo' e o 'Reconhecimento do trabalho' pelos usuários foram os itens apontados com maior frequência. Vale ressaltar que a 'Falta de reconhecimento' tem provocado alterações nos modos de vivenciar o trabalho, o que é percebido na diminuição no seu ritmo de trabalho, como evidenciado na fala a seguir:

Quando comecei no atendimento especializado, comecei a evoluir até chegar ao ponto de atender noventa pessoas ao dia. Então por algum motivo dei uma decaída, pois nós, seres humanos, não somos como máquinas, somos movidos por sentimentos e emoções, e nossa vida é composta de altos e baixos. Então fui chamado a atenção de forma educada, mas vigorosa, dizendo que eu podia fazer melhor. Depois disso, nunca mais fui o mesmo (N6).

Tais informações são úteis para ilustrar alguns dos elementos presentes no cotidiano de trabalho dos servidores do INSS e, numa perspectiva mais ampla, relacionam-se com as representações negativas da sociedade sobre o serviço público, considerado ineficiente, burocrático e oneroso (Ribeiro e Mancebo, 2013).

A propósito, no Brasil, no primeiro governo sob a presidência de Fernando Henrique Cardoso, a retórica da excelência no serviço público, em face do modelo burocrático, inscreveu-se nas diretrizes da Reforma Administrativa do Estado, visando à maior eficiência e eficácia da máquina pública (BresserPereira, 1997). Também denominada NGP (Araújo e Castro, 2011), tal visão apregoa rígido controle sobre o desempenho dos servidores públicos com o argumento de qualificar o serviço oferecido à sociedade. Embora antecedida pela palavra nova, uma revisão bibliográfica (Goulart, Sousa e Blanch, 2015) aponta que se trata de uma antiga estratégia da administração clássica inscrita na máxima exploração do trabalho com o mínimo de investimentos. Gaulejac (2007) refere-se a esse novo modelo de gestão como um conjunto de técnicas e saberes práticos que visam orientar condutas e estabelecer uma cultura corporativa que mobilize subjetividades polivalentes, criativas e flexíveis capazes de superar as dificuldades, mas sem questioná-las.

A PS não se exclui dessa perspectiva. Em seu plano de desenvolvimento intsitucional para o período 2016-2019, consta que a 'governança corporativa' é o modelo que estabelece a orientação estratégica de gestão, com foco nos resultados, sendo considerada uma referência no âmbito da administração pública federal (Brasil, 2015).

\section{A organização e a pessoa}


O conjunto de escalas que avalia o quanto a pessoa está ajustada e adaptada à organização (0-10) obteve média de 6,95 (DP=1,49). Esta média sinaliza uma satisfação laboral moderada. O item com maior frequência de respostas foi 'Me faz sentir útil' $(8,52)$, enquanto a menor frequência coube ao item 'Me dá a sensação de liberdade' $(6,78)$.

O sentimento de 'satisfação' foi relacionado, nas narrativas, à função pública, como um dever inerente ao exercício da função, como se lê a seguir:

Entrei na casa sentindo muito orgulho em fazer parte de um órgão que garante o exercício de um direito básico de cidadania, o direito à Previdência Social, previsto na Constituição Federal, e que gera tanto impacto na sociedade como um todo (N4).

A visão de mundo, centrada na ética do serviço público, foi relacionada a dilemas de consciência e prejuízos individuais diante de um sistema que se rege por resultados a curto prazo, conforme observado a seguir:

É preciso ler com atenção. Unir os documentos. E isso torna mais difícil o cumprimento das metas. Então quem acaba se dando mal é quem tá preocupado em fazer a coisa certa (N8).

Para Gomes (2014), ao lidar com os valores humanos e a ética, são requeridas do servidor público certas habilidades que lhe permitam fazer escolhas que repercutem em si mesmo, no outro e no coletivo.

\section{As condições de bem-estar no trabalho e saúde}

O resultado do conjunto de escalas que tratam do bem-estar (0-7) foi de 4,99 $(\mathrm{DP}=1,13)$. O 'bem-estar psicossocial' foi valorado em 5,0 $(\mathrm{DP}=1,16)$, média positiva, estando mais próxima do bem-estar que do mal-estar. O item com menor frequência de respostas $(4,30)$ diz respeito à 'impotência-potência', enquanto a maior frequência $(5,74)$ refere-se à 'moralidade-imoralidade'. Os dados apontam para um leve sentimento de impotência ante o trabalho e uma valoração da moralidade.

\section{Motivação, sentido do trabalho, rendimento no trabalho}

A escala que avalia aspectos como motivação, sentido do trabalho e rendimento no trabalho (0-7) obteve média geral de 4,93 ( $\mathrm{DP}=1,15)$, indicando moderada expectativa em relação à qualidade do trabalho na organização. Nesta escala, o item com menor frequência de respostas $(3,90)$ diz respeito a 'Minhas oportunidades de promoção de trabalho', e o item com maior frequência de respostas 
$(6,16)$ refere-se a 'Meu compromisso com o trabalho'. Estes números sinalizam que os sujeitos têm poucas expectativas com relação à promoção ou ascensão na carreira profisional, embora apontem expressivo compromisso com o trabalho.

Por sua vez, o compromisso com o trabalho, um item quantitativamente valorado na maior parte das respostas, pode ser afetado em decorrência de a gestão dar maior evidência ao cumprimento de metas e não à qualidade do trabalho. $\mathrm{O}$ aspecto do compromisso, hoje parecendo mais tênue, é expresso no trecho a seguir:

Quando entrei, tinha dificuldade em esquecer dos segurados. Levava-os para casa comigo em pensamento. Tinha dificuldade para dormir e relaxar, pois estava empenhada em fazer o setor dar certo. (...) agora, tenho menos tempo para pensar nos segurados, mas ainda acordo e o primeiro pensamento que vem é em alguém que atendi ou devo atender (N5).

Gaulejac (2007) assevera que, em grande parte dos casos, os indivíduos submetidos a modelos de gestão do trabalho perpassados pela cobrança sistemática de metas e resultados tendem a se fragmentar internamente ou, então, mergulhar na hiperatividade para não pensarem na dinâmica em que estão envolvidos, o que culmina em sofrimento, podendo levar à perda do sentido da própria vida.

\section{Efeitos 'colaterais' para a saúde: desgaste, esgotamento, transtornos}

A escala 'Efeitos colaterais', que se refere a desgaste emocional, esgotamento físico, transtornos digestivos, dores de cabeça (0-7), obteve uma pontuação média de 3,05 (DP=1,49). Esta média sinaliza que cerca da metade dos participantes percebe efeitos negativos decorrentes do trabalho. $\mathrm{O}$ item com menor frequência de respostas $(3,36)$ diz respeito a 'transtornos digestivos', e o item com maior número de respostas refere-se a 'tensões musculares, esgotamento mental' $(5,25)$ e 'dores nas costas' $(5,05)$.

O resultado da análise relacionada às quatro palavras-chave, incritas na pergunta aberta n. 1, 'Defina a experiência de trabalho atual', foram: dor, desgaste, atendimento e reconhecimento. Tais informações se conectam com os dados numéricos.

Os efeitos relacionados à saúde foram relatados em todas as nove narrativas, como se lê a seguir:

Comecei a ter acompanhamento com psiquiatra e fazer uso de ansiolítico. Sei que está relacionado a todo o meu contexto de vida, mas o trabalho tem, sim, sua contribuição direta. Especialmente no contexto atual, de total desrespeito aos direitos 
e instabilidade por reformas, que me impactou muito, porque a gente vê, ouve injustiça e não tem muito a fazer (N6).

O pano de fundo dos aspectos aqui analisados tem como marco o ano de 2008, quando se verificaram intensas alterações nas condições de trabalho dos servidores do INSS, com implantação do novo modelo de gestão na autarquia, o que trouxe reflexos importantes para a saúde dos trabalhadores (Carvalho e Leite, 2011).

Conforme mostra o relatório final da situação de saúde dos servidores do INSS, de iniciativa da Auditoria Geral do órgão (Carvalho e Leite, 2011), houve um aumento da carga horária de trabalho, atingindo um mínimo de nove horas diárias. Além disso, o documento refere implantação de um sistema de gratificação vinculado ao cumprimento de metas institucionais, o que capacitaria o servidor a receber $80 \%$ do valor da Gratificação de Desempenho de Atividade do Seguro Social (GDASS). Ademais, foi implantado um sistema de avaliação de desempenho cujo resultado impacta em até $20 \%$ o valor dessa gratificação, o que, no total, corresponde à maior parte da remuneração. Finalmente, figura o decréscimo do quadro de pessoal, sobretudo em razão de aposentadorias massivas, o que fez aumentar a carga de trabalho dos que permaneceram na ativa.

Partimos do pressuposto de que essas alterações, fundamentadas num modelo de gestão que, em linhas gerais, adota a lógica do mercado, visando à maior produtividade no serviço público, sob a alegação da busca do bem comum, implicam mudanças nos modos de viver e significar o trabalho (Blanch e Stecher, 2010).

No que tange ao escopo da pesquisa aqui apresentada, Carvalho e Leite (2011) mostram um acentuado número de licenças médicas para tratamento de saúde de servidores do INSS. Ademais, acrescentam que predomina um despreparo de servidores em cargo de gestão que recebem a função por indicação política e, não raras vezes, atuam de forma autoritária, com repercussões na esfera psicoafetiva, o que pode caracterizar o chamado assédio moral (Glina e Soboll, 2012). Vale ressaltar que as repercussões psicológicas decorrentes do trabalho já são a segunda causa de afastamento do trabalho no mundo (Rodrigues de Paula, 2015).

Do ponto de vista dos gestores executivos entrevistados, a causa do malestar no trabalho expresso indiretamente no absenteísmo deveu-se à capacitação insuficiente do servidor, ou seja, imputa-se culpa à vítima, além de ele ser constrangido pela cultura da punição.

Interessante perspectiva é apontada por Rodrigues de Paula (2015), servidor do INSS, que vincula o assédio moral à falência da ética na modernidade. $\mathrm{O}$ autor descreve a própria situação de violência psicológica sofrida no trabalho com ênfase nos modos de enfrentamento, fazendo uma crítica à subordina- 
ção moral vigente, que zela pelo cumprimento da ordem e da produção, em detrimento do que contribui para proteger a qualidade de vida no trabalho.

\section{Considerações finais}

Os resultados da pesquisa aqui apresentada sugerem que a gestão do trabalho de cunho 'gerencialista' adotada nos serviços públicos, aliada às medidas governamentais colocadas em marcha, ou seja, a Reforma da PS (Brasil, 2016a), atingem as condições de vida e de trabalho dos servidores do INSS. As reformas de grande calibre, assentadas no desmonte do Ministério da Previdência Social e no anúncio da redução de direitos constitucionais (Fagnani, 2016), afetam tanto os servidores quanto os segurados do INSS.

$\mathrm{O}$ atendimento na linha de frente do INSS torna-se uma vitrine na qual as pessoas em situação de vulnerabilidade e temendo cortes de direitos previdenciários buscam respostas para seus anseios. A carga emocional e a tensão dos segurados, acentuada pela atual conjuntura econômica, foram apontadas como um elemento disparador de sofrimento psíquico e físico nos servidores, ao que se alia a gestão baseada na cobrança de metas de produtividade, que no caso da PS responde pelo nome de 'governança corporativa' (Brasil, 2015). Tal modelo de gestão, como se observa neste estudo, tem impacto direto sobre o nível do salário, o que é remediado por meio das gratificações que constituem grande parte dos vencimentos auferidos, com sobrecarga de trabalho.

Constatamos também que ressaltam dilemas éticos, inscritos na falta de tempo apontada pela maioria dos participantes, em decorrência das metas de curto prazo. Ademais, a dificuldade no acompanhamento dos processos dos segurados, cujo ritmo é semelhante a uma linha de montagem, torna a produção mais rápida, mas impede que o trabalhador perceba o resultado final do seu trabalho.

Ponderamos que o compromisso com o trabalho, retratado na relação afetiva por parte de servidores com os segurados, representa um modo de significar o trabalho (Blanch, 2003; Goulart, 2009) que, neste caso, liga-se ao bem comum, ou seja, uma atividade que envolve o acesso a direitos sociais de uma coletividade, criando-se uma empatia entre servidor e segurado. Nessa perspectiva, os modos de sentir e vivenciar o trabalho confrontam-se com a lógica mercantil adotada em serviços de utilidade pública como os da PS.

Gomes (2014) chama a atenção para a racionalidade da administração pública, que implica diretamente as ações e condutas morais dos indivíduos, sendo que a moral da racionalidade sobressai em relação à moral das relações. Ou seja, a tendência é que a pessoa sofra com dilemas éticos entre o que é certo ou equivocado, mas cumpra os protocolos, mesmo a contragosto.

Avaliamos que o mal-estar detectado decorre de um embate cotidiano de valores, bem retratado por Gaulejac (2007), quando refere que a experiência 
humana passa a ser traduzida em cálculo, baseado em índices e indicadores meritocráticos que convertem as pessoas em fator econômico equivalente às matérias-primas e aos meios de produção.

Os relatos acerca do despreparo técnico para o exercício da função, numa primeira leitura, poderiam ser relacionados à conduta individual, isto é: cumpre ao trabalhador suprir tal deficiência. Entretanto, os resultados obtidos sugerem que a colocação/exposição dos servidores recém-contratados 'na linha de frente', sem preparação prévia, é uma lacuna a ser preenchida pela instituição. Tal situação, aliada ao déficit de trabalhadores (Carvalho e Leite, 2011; Triches, 2012; Ribeiro e Mancebo, 2013), pode resultar em prejuízos para os segurados, seja na postergação, seja na restrição do acesso aos benefícios previdenciários. Ademais, a falta de pessoal reflete-se no trabalhador que se torna alvo de violência física ou psicológica, ao que pode se associar o assédio moral (Glina e Soboll, 2012; Rodrigues de Paula, 2015).

Em síntese, a transposição do modelo de gestão empresarial ou a incorporação do espírito de negócio privado para o serviço público suscita um paradoxo. O nó da questão parece estar relacionado à ênfase nos resultados em detrimento da valorização/qualificação do processo de trabalho, o que, segundo os achados, tem trazido alguns benefícios, como maior agilidade no encaminhamento das demandas. Todavia, a realização do trabalho em menor espaço de tempo não representa ou garante a qualidade do processo, podendo, inclusive, culminar em perdas para os segurados e danos à saúde dos trabalhadores.

Alguns trabalhadores parecem naturalizar a realidade existente, enquanto outros reagem com indignação ou sofrimento psíquico. Estes têm vivenciado uma ressignificação do trabalho, o que requer atenção a variáveis como idade, gênero e função. Citamos, a título de exemplo, a atuação dos médicos peritos, uma categoria profissional central nas ações da PS, necessitando de maior aprofundamento da análise do seu papel no âmbito do acesso aos benefícios previdenciários. Trata-se de um dos limites do estudo aqui apresentado e que deve ser objeto de aprofundamento.

Consideramos que a diversidade de técnicas adotadas no estudo contribuiu para melhor compreensão do objeto, sendo que o recurso das narrativas mostrou-se potente como caminho para a autorreflexão.

Esperamos que os resultados, uma vez apropriados pelos sujeitos, compromisso esse assumido pelos pesquisadores, sirvam de disparadores para ações de cunho coletivo ou sindical, além da conduta individual de enfrentamento. A socialmente nefasta conjuntura econômica e política do país traz-nos mais dúvidas que certezas... 


\section{Colaboradores}

Patrícia Martins Goulart foi responsável pelo desenho do estudo, discussão, redação e revisão do texto. Francisco Antonio de Castro Lacaz e Edvânia Ângela de Souza Lourenço participaram da discussão, redação e revisão de conteúdo do manuscrito.

Resumen El objetivo de este estudio cuantitativo y cualitativo es conocer y analizar las condiciones de trabajo de los servidores públicos que se desempeñan en el Instituto Nacional de Seguro Social vinculados a la Seguridad Social del sur de Santa Catarina, con énfasis en las implicaciones en su salud. Se trató de un estudio exploratorio realizado entre el 2013 y el 2017. Participaron del mismo 165 trabajadores vinculados a 11 agencias del Instituto Nacional de Seguro Social de dicha región, que respondieron un cuestionario con escalas sobre condiciones de trabajo y bienestar asociadas a preguntas abiertas. En un segundo momento se adoptó la técnica descriptiva, a fin de complementar la información. El promedio obtenido de los resultados de las escalas de condiciones de trabajo (0-10) fue de 6,65 (DP = 1,39), mientras que en lo que se refiere al bienestar (0-7) el promedio fue de 4,99 (DP = 1,13). Se observaron dilemas éticos derivados de la calidad del trabajo, en función que se prioriza el alcance de metas cuantitativas debido a la penetración de la lógica privada en la gestión del trabajo en el espacio público. Se concluyó que las condiciones de trabajo y bienestar tienen repercusiones negativas para la salud de los trabajadores.

Palabras clave gestión; trabajo; salud; seguridad social; trabajadores.

\section{Notas}

${ }^{1}$ Universidade Federal de São Paulo, São Paulo, SP, Brasil.

<pmg.correio@gmail.com>

Correspondência: Universidade Federal de São Paulo, Campus Baixada Santista, rua Silva Jardim, 136, CEP 11015-020, Vila Mathias, Santos, São Paulo, Brasil.

${ }^{2}$ Universidade Federal de São Paulo, Escola Paulista de Medicina, Departamento de Medicina Preventiva, São Paulo, SP, Brasil.

$<$ f.lacaz@unifesp.br>

${ }^{3}$ Universidade Estadual Paulista Júlio de Mesquita Filho, Faculdade de Ciências Humanas e Sociais, Departamento de Serviço Social, Franca, SP, Brasil.

<edvaniaangela@hotmail.com> 


\section{Referências}

ALVES, Giovani. Trabalho e subjetividade: o espírito do toyotismo na era do capitalismo manipulatório. São Paulo: Boitempo, 2011.

ANDERSON, Perry. Balanço do neoliberalismo. In: SADER, Emir; GENTILI, Pablo (orgs.). Pós-neoliberalismo: as políticas sociais e o Estado. Rio de Janeiro: Paz e Terra, 1995. p. 9-23.

ANTUNES, Ricardo; DRUCK, Graça. A terceirização sem limites: a precarização do trabalho como regra. O Social em Questão, Rio de Janeiro, n. 34, p. 19-40, 2015. Disponível em: <http://www.cressrn.org.br/files/arquivos/Sm4618UP754c17102374.pdf>. Acesso em: 12 mar. 2017.

ARAÚJO, Suêldes; CASTRO, Alda M. D. A. Gestão educativa gerencial: superação do modelo burocrático? Ensaio: Avaliação e Políticas Públicas em Educação, Rio de Janeiro, v. 19, n. 70, p. 81-106, 2011. Disponível em: <http://www.scielo.br/ scielo.php?script $=$ sci_arttext $\&$ pid $=$ S0104$40362011000100006 \& \operatorname{lng}=$ pt $\& \mathrm{nrm}=$ iso $>$. Acesso em: 13 jul. 2017.

BANDEIRA, Luiz A. M. As políticas neoliberais e a crise na América do Sul. Revista Brasileira de Política Internacional, Brasília, v. 45, n. 2, p. 135-146, 2002. Disponível em: <http:// www.scielo.br/scielo.php?script $=$ sci_arttex t\&pid=S0034-73292002000200007>. Acesso em: 11 maio 2018.

BLANCH, Josep M. Trabajar en la modernidad industrial. In: BLANCH, Josep M. (coord.); TOMÁS, Maria Jesús E.; ARTILES, Carolina Gala D.; MARTÍN, Antonio. Teoría de las relaciones laborales: fundamentos. Barcelona: UOC, 2003. p. 13-148.

BLANCH, Josep M. Calidad de vida laboral en hospitales y universidades mercantilizados. Papeles del psicólogo, Madri, v. 35, n. 1, p. 40-47, 2014. Disponível em: <http://www. redalyc.org/articulo.oa?id $=77830184006>$. Acesso em: 15 jun. 2016.
BLANCH, Josep M. et al. Cuestionario de bienestar laboral general: estructura y propiedades psicométricas. Revista de Psicología del Trabajo y de las Organizaciones, Madri, v. 26, n. 2, p. 157-170, 2010. Disponível em: <http://www. redalyc.org/articulo.oa?id=231316500007>. Acesso em: 15 jun. 2016.

BLANCH, Josep M.; SAHAGÚN, Miguel; CERVANTES, Genís. Estructura factorial del cuestionario de condiciones de trabajo. Revista de Psicología del Trabajo y de las Organizaciones, Madri, v. 26, n. 3, p. 175-189, 2010. Disponível em: <http:// scielo.isciii.es/scielo.php?script=sci_arttext\& pid $=$ S1576-59622010000300002 > . Acesso em: 15 jun. 2016.

BLANCH, Josep M.; STECHER, Antônio. Organizaciones excelentes como factores de riesgo psicosocial. In: CARRILLO, Marco A. (org.). Psicología y Trabajo: experiencias de investigación en Iberoamérica. México: U. A. Querétaro, 2010. p. 88-109.

BRASIL. Decreto n. 6.833, de 29 de abril de 2009. Dispõe sobre o Subsistema Integrado de Atenção à Saúde do Servidor Público Federal-SIASS e o Comitê Gestor de Atenção à Saúde do Servidor. Diário Oficial da União, Poder Executivo, Brasília, DF, 29 abr. 2009. Disponível em: <http://www.planalto.gov. br/ccivil_03/_ato2007-2010/2009/decreto/ d6833.htm>. Acesso em: 17 ago. 2016.

BRASIL. Ministério da Previdência Social. Caderno de Governança Corporativa: cadeia de valor integrada - Plano Estratégico Institucional 2016-2019. Brasília, DF: Ministério da Previdência Social, 2015. Disponível em: <http://www.previdencia.gov.br/wp-content/uploads/2012/11/ Caderno_de_Governan\%C3\%A7a_Corporativa_PS_vR1.pdf>. Acesso em: 17 out. 2016.

BRASIL. Portal do Senado. Senado aprova impeachment de Dilma Rousseff. set. 2016a. Disponível em: < https://www12.senado.leg. $\mathrm{br} /$ noticias/materias/2016/12/28/impeachmentde-dilma-rousseff-marca-ano-de-2016-no-congresso-e-no-brasil>. Acesso em: 11 maio. 2018. 
BRASIL. Portal do Senado. Câmara dos Deputados aprova projeto de modernização da legislação trabalhista. 2016b. Disponível em: $<$ http://www.brasil.gov.br/governo/2017/04/ camara-dos-deputados-aprova-projeto-demodernizacao-da-legislacao-trabalhista $>$. Acesso em: 12 mar. 2017.

BRASIL. Portal do Senado. Michel Temer sanciona a reforma ministerial com vetos parciais. 2016c. Disponível em: <http://www12. senado.leg.br/noticias/materias/2016/09/30/ michel-temer-sanciona-a-reforma-ministerialcom-vetos-parciais>. Acesso em: $17 \mathrm{dez} .2016$.

BRASIL. Medida provisória n. 808, de 14 de novembro de 2017. Altera a Consolidação das Leis do Trabalho (CLT), aprovada pelo decreto-lei n. 5.452, de $1^{\circ}$ de maio de 1943. Diário Oficial da União, Poder Executivo, Brasília, DF, 14 nov. 2017. Disponível em <http://www.planalto. gov.br/ccivil_03/_ato2015-2018/2017/Mpv/ mpv808.htm\#art2 >. Acesso em: $1^{\circ}$ dez. 2017.

BRAZ, Marcelo. O golpe nas ilusões democráticas e a ascensão do conservadorismo reacionário. Serviço Social \& Sociedade, São Paulo, n. 128, p. 85-103, 2017. Disponível em: $<$ http://www.scielo.br/scielo.php?pid=S0101$66282017000100085 \&$ script $=$ sci_arttext $>$. Acesso em: 23 maio 2017.

BRESSER-PEREIRA, Luiz C. A reforma do Estado dos anos 90: lógica e mecanismos de controle. Brasília: Ministério da Administração Federal e Reforma do Estado, 1997. Disponível em: <http://www.bresserpereira.org.br/ documents/MARE/CadernosMare/CADERNO01. pdf >. Acesso em: 11 ago. 2016.

CARVALHO, Suely F.; LEITE, Jane C. M. Saúde INSS 2011: uma análise da situação de saúde dos servidores do INSS. Relatório final, 2011. Disponível em: < https://peritomed.files.wordpress.com/2011/12/relatorio_consolidado_programa_091.pdf>. Acesso em: 11 ago. 2016.

CHRISTO, Cirlene S.; BORGES, Maria E. S. Reorganização do trabalho em uma agência da Previdência Social: resistência à mudança ou preservação da saúde? Saúde em Debate, Rio de
Janeiro, v. 41, n. 2, p. 104-114, 2017. Disponível em: <http://www.scielo.br/scielo.php?script=sci_ arttext\&pid=S0103-11042017000600104\&lng= pt\&nrm=iso >. Acesso em: 19 dez. 2017.

DARDOT, Pierre; LAVAL, Christian. A nova razão do mundo: ensaios sobre a sociedade neoliberal. São Paulo: Boitempo, 2016.

DATAPREV. Empresa de Tecnologia e Informação da Previdência Social. A virada da Previdência Social: como acabaram as filas nas portas das agências. Brasília: Dataprev, 2013. Disponível em: <http://portal.dataprev.gov. $\mathrm{br} /$ sites/default/files/arquivos/viradadegestao2013webl.pdf>. Acesso em: 11 maio 2018.

DIENER, Edward; TAY, Louis; OISHI, Shigehiro. Rising income and the subjective well-being of nations. Journal of Personality and Social, Washington, DC, v. 104, n. 2, p. 267-276, 2013. Disponível em: <https://www.ncbi. nlm.nih.gov/pubmed/23106249>. Acesso em: 15 fev. 2014.

FAGNANI, Eduardo. Previdência Social: reformar ou destruir? In: JINKINGS, Ivana; DORIA, Kim; CLETO, Murilo (orgs.). Por que gritamos golpe?: para entender o impeachment e a crise. São Paulo: Boitempo, 2016. p. 85-92.

FREITAS, Henrique; MOSCAROLA, Jean. Análise de dados quantitativos e qualitativos: casos aplicados usando o Sphinx. Porto Alegre, Sphinx: 2000. Disponível em: < http://www.sphinxbrasil.com/ uploads/files/ANALISE_DE_DADOS_QUANTITATIVOS_\&_QUALITATIVOS_Casos_aplicados_usando_o_Sphinx__2000.pdf > . Acesso em: 11 fev. 2016.

GAULEJAC, Vincent. Gestão como doença social: ideologia, poder gerencialista e fragmentação social. Aparecida: Ideias e Letras, 2007.

GENTIL, Denise. Politica fiscal e falsa crise da Seguridade Social brasileira: análise financeira do período 1990-2006. 245f. Tese (Doutorado em Economia) - Universidade Federal do Rio de Janeiro, Rio de Janeiro, 2006. Disponível em: <http://www.ie.ufrj.br/images/pesquisa/ 
publicacoes/teses/2006/a_politica_fiscal_e_a_ falsa_crise_da_seguraridade_social_brasileira_ analise_financeira_do_periodo_1990_2005. pdf>. Acesso em: 11 fev. 2016.

GLINA, Débora M. R.; SOBOLL, Lis A. Intervenções em assédio moral no trabalho: uma revisão da literatura. Revista Brasileira de Saúde Ocupacional, São Paulo, v. 37, n. 126, p. 269-283, 2012. Disponível em: $<$ http://www.scielo.br/scielo.php?script=sci_art text\&pid=S0303-76572012000200008 $>$. Acesso em: 13 jul. 2017.

GOMES, Nanci F. Ética na administração pública: desafios e possibilidades. Revista de Administração Pública, Rio de Janeiro, v. 48 , n. 4, p. 1.029-1.050, 2014. Disponível em: <http://bibliotecadigital.fgv.br/ojs/ index.php/rap/article/view/30916>. Acesso em: 18 jan. 2017.

GONÇALVES, Reinaldo. Novo desenvolvimentismo e liberalismo enraizado. Serviço Social \& Sociedade, São Paulo, n. 112, p. 637-671, 2012. Disponível em: <http://www.scielo.br/scielo. php?pid=S0101-66282012000400003\&script $=$ sci_ abstract\&tlng $=$ pt $>$. Acesso em: 11 maio 2018.

GOULART, Patrícia M. O significado do trabalho: delimitações teóricas (1955-2006). Cadernos de Psicologia Social do Trabalho, São Paulo, v. 12, n. 1, p. 47-55, 2009. Disponível em: <http:// pepsic.bvsalud.org/scielo.php?script=sci_abstr act $\&$ pid $=$ S1516-37172009000100005 $>$. Acesso em: 11 maio 2017.

GOULART, Patrícia M. et al. Questionário de bem-estar no trabalho: estrutura e propriedades psicométricas. Estudos de Psicologia, Campinas, v. 29, supl. 1, p. 657-665, 2012. Disponível em: $<$ http://www.scielo.br/scielo.php?pid=S0103$166 \mathrm{X} 2012000500002 \& \mathrm{script}=\mathrm{sci}$ abstract\&tlng $=$ pt $>$. Acesso em: 11 maio 2017.

GOULART, Patrícia M.; SOUSA, Indianara; BLANCH, Josep M. Gestão pública municipal sob a lógica empresarial: sentidos e significados. In: YAMAGUCHI, Cristina; WATANABE, Melissa (orgs.). Temas contemporâneos em ciências sociais aplicadas. Criciúma: Edinesc, 2015. p. 59-71.
LACAZ, Francisco A. C. O campo saúde do trabalhador: resgatando conhecimentos e práticas sobre as relações trabalho-saúde. Cadernos de Saúde Pública, Rio de Janeiro, v. 23, n. 4, p. 757-766, 2007.

LACAZ, Francisco A. C.; GOULART, Patrícia M.; JUNQUEIRA, Virgínia (orgs.). Trabalhar no SUS: gestão, repercussões psicossociais e política de proteção à saúde. São Paulo: Hucitec, 2017.

LIMA, Alexandre B. Tecnologias de informação, cotidianos e psicologia social: considerações teórico-metodológicas. Psicologia \& Sociedade, Belo Horizonte, v. 25, n. 1, p. 10-18, 2013. Disponível em: <http://www.scielo.br/ scielo.php?script $=$ sci_arttext $\&$ pid $=$ S0102$71822013000100003 \& \operatorname{lng}=$ pt\&nrm $=$ iso $>$. Acesso em: 29 jun. 2017.

LOURENÇO, Edvânia. Terceirização: a derruição de direitos e a destruição da saúde dos trabalhadores. Serviço Social \& Sociedade, São Paulo, v. esp., p. 447-475, 2015. Disponível em: $<$ http://www.scielo.br/scielo.php?pid=S0101$66282015000300447 \& \mathrm{script}=\mathrm{sci}$ abstract\&tlng $=$ pt $>$. Acesso em: 11 maio 2018.

LOURENÇO, Edvânia A. S. Saúde do/a trabalhador/a no capitalismo contemporâneo. In: LOURENÇO, Edvânia A. S. (org.). Saúde do/a trabalhador/a e serviço social: estudos da relação trabalho e saúde no capitalismo contemporâneo. Campinas: Papel Social, 2016. p. 25-47.

LOURENÇO, Edvânia A. S.; LACAZ, Francisco A. C.; GOULART, Patrícia M. Crise do capital e o desmonte da Previdência Social no Brasil. Serviço Social \& Sociedade, São Paulo, n. 130, p. 467-486, 2017. Disponível em: <http:// www.scielo.br/scielo.php? pid =S0101$66282017000300467 \&$ script $=$ sci_arttext $>$. Acesso em: 30 nov. 2017.

MARTINS, Maria I. C. et al. A política de atenção à saúde do servidor público federal no Brasil: atores, trajetórias e desafios. Ciência \& Saúde Coletiva, Rio de Janeiro, v. 22, n. 5, p. 1.429-1.440, 2017. 
MEIHY, José C. S. B. Manual de história oral. São Paulo: Loyola, 2005.

MUYLAERT, Camila J. et al. Entrevistas narrativas: um importante recurso em pesquisa qualitativa. Revista da Escola de Enfermagem da USP, São Paulo, v. 48, n. 2, p. 184-189, 2014. Disponível em: <http://www.scielo.br/ pdf/reeusp/v48nspe2/pt_0080-6234-reeusp-48nspe2-00184.pdf>. Acesso em: 22 jun. 2016.

NAVARRO, Vera L.; LOURENÇO, Edvânia A. S. $O$ avesso do trabalho $I V$ : terceirização: precarização e adoecimento no mundo do trabalho. São Paulo: Expressão Popular, 2017.

PRADO, Fernanda O.; DUARTE, Evaristo E. C. A racionalização do trabalho dos assistentes sociais do INSS. Revista Katálysis, Florianópolis, v. 18, n. 2, p. 162-171, 2015. Disponível em: <http://www.scielo.br/scielo. php?pid=S1414-49802015000200162\&script $=$ sci_ abstract\&tlng =pt>. Acesso em: 19 dez. 2017.

RIBEIRO, Carla V. S.; MANCEBO, Deise. O servidor público no mundo do trabalho do século XXI. Psicologia: ciência e profissão, Brasília, v. 33, n. 1, p. 192-207, 2013. Disponível em: <http:// www.scielo.br/scielo.php?script $=$ sci_arttex t\&pid=S1414-98932013000100015>. Acesso em: 13 jul. 2017.

RODRIGUES DE PAULA, Cleber. Assédio moral, trabalho e sofrimento: um olhar ético. In: OLIVEIRA, Renato T.; TOLFO, Suzana R. (orgs.). Assédio moral no trabalho: características e intervenções. 1. ed. Florianópolis: Lagoa, 2015. p. 223-250.

SENNETT, Richard. A cultura do novo capitalismo. Rio de Janeiro: Record, 2006.

SILVA, Luis F. Progressão funcional a cada 12 meses/INSS. Sindicato dos Trabalhadores em Saúde e Previdência do Serviço Público Federal no Estado de Santa Catarina (Sindprevs-SC). Seção Informes. Florianópolis, 2017. Disponível em: $<$ http://www.sindprevs-sc.org.br/juridico-1/ informes/5710-progressao-funcional-a-cada-12meses-inss >. Acesso em: 9 dez. 2017.
SINDICATO DOS TRABALHADORES EM SAÚDE E PREVIDÊNCIA DO SERVIÇO PÚBLICO FEDERAL NO ESTADO DE SANTA CATARINA (SINDPREVS-SC). Propostas II Seminário de Saúde do Trabalhador. Disponível em: <http://www. sindprevs-sc.org.br/66-saude-do-trabalhador/3632propostas-ii-seminario-de-saude-do-trabalhador $>$. Acesso em: 12 dez. 2013.

SINDICATO DOS TRABALHADORES EM SAÚDE E PREVIDÊNCIA DO SERVIÇO PÚBLICO FEDERAL NO ESTADO DE SANTA CATARINA (SINDPREVSSC). Greve acaba, mas a luta segue! Boletim de Greve, Florianópolis, n. 34, p. 1-2, 29 set. 2015. Disponível em < http://www.sindprevs-sc.org.br/ publicacoes-1/boletins-de-greve/4863-boletimde-gre-n-34> . Acesso em: 13 fev. 2017.

SOUZA, Helton S.; MENDES, Áquilas N. A terceirização e o 'desmonte' do emprego estável em hospitais. Revista da Escola de Enfermagem da USP, São Paulo, v. 50, n. 2, p. 286-294, 2016. Disponível em: <http:// www.scielo.br/pdf/reeusp/v50n2/pt_00806234-reeusp-50-02-0286.pdf>. Acesso em: 13 fev. 2017.

TRAESEL, Elisete S.; MERLO, Álvaro R. C. 'Somos sobreviventes': vivências de servidores públicos de uma instituição de seguridade social diante dos novos modos de gestão e a precarização do trabalho na reforma gerencial do serviço público. Cadernos de Psicologia Social do Trabalho, São Paulo, v. 17, n. 2, p. 224-238, 2014. Disponível em: <http://www.revistas.usp.br/cpst/article/ view/112344/110308>. Acesso em: 13 fev. 2017.

TRICHES, Alexandre S. Identificando importantes causas geradoras de litigiosidade envolvendo INSS e segurado da Previdência Social. Revista de Previdência Social, Brasília, v. 36, n. 380, p. 572-578, 2012. Disponível em: <http:// www.alexandretriches.com.br/identificandoimportantes-causas-geradoras-de-litigiosidadeenvolvendo-inss-e-segurado-da-previdenciasocial>. Acesso em: 13 fev. 2017.

Recebido em 05/08/2017.

Aprovado em 13/03/2018. 